\title{
Asymptomatic Old Female Patient with Left Atrial Myxoma Originating from Pulmoary Vein
}

\author{
Cetin Sanlialp Sara ${ }^{\star, \dagger}$ \\ MD, Department of Cardiology, Servergazi State Hospital, Denizli, Turkey
}

DOI: https://doi.org/10.15520/ijmhs.v9i6.2617

Accepted 15 Jun 2019; Received 15 May 2019; Publish Online 30 Jun 2019

\author{
Reviewed By: Dr. \\ Daniel V. \\ Department: Medical
}

\begin{abstract}
Myxomas are the most common benign tumors of the heart and are often located in the left atrium and interatrial septum. They are rarely seen in the right atrium and ventricles. Myxoma usually has a benign character, but when it reaches large volumes it causes severe mechanical obstructive symptoms in patients. Shortness of breath, dizziness, cough, palpitation may be its symptoms. Also constitutional complaints such as fever, myalgia and weight loss can be seen in patients. This case is about a 82 -year-old female patient with large size atrial mxyoma that was detected by echocardiography.
\end{abstract}

Key words: asymptomatic-left atrium-myxoma-pulmonary vein

\section{INTRODUCTION}

Cardiac myxoma is a benign cardiac tumor that constitutes approximately $80 \%$ of the all cardiac tumors. Cardiac myxomas can devalope in any cavities of heart but $90 \%$ of them are located in left atrium and they are originated from fossa ovalis [1] . They are generally seen in women aged 50-60 years [2] . It has different clinic presentations according to its placement into heart [3]. While approximately $50 \%$ of patients with myxoma have clinial symptoms due to peripheral embolism or intracardiac obtruction, $10 \%$ of patients with myxoma have no symptoms [4]. In this case, we planned to present an old female patient with lef atrial mixoma that was unusual originated from pulmonary vein

\section{CASE REPORT}

An 82-years old female patient was consulted to cardiology department by the orthopedics before the knee operation. The patient had no cardiac story and medical treatment in her past. She had no diabetes mellitus or hipertension in spite of his advanced age. Her blood pressure was 100/70 mmhg, her heart beat was $106 / \mathrm{min}$. Her blood test was normal. There was sinus tachycardia in her electrocardiogram. She had 1-2/6 systolic murmur in apical region so echocardiography was planned. In echocardiographic 4- chambers

\footnotetext{
* Corresponding author.

$\dagger$ Email: saracetin@hotmail.com.tr.
}

imaging, it was seen a fragmented and hyperechogenic mass $(28 \times 55 \mathrm{~mm})$ originating from pulmonary vein. The mass was stretched towards the left atrium base and restricted the internal flow of the ventricle. After transesophageal echocardiography, the mass was evaluated as myxoma and it was observed that it had developed in pulmonary vein. Cardiac angiographic CT and operation were recommended to her but she refused.

\section{DISCUSSTON}

Myxoma is a primer benign cardiac tumor that is seen as $0.3 \%$ in population [4]. It can cause symptoms due to its location, the degree of obstruction and its interference with valves or circulation. It usally presents with syncope, dispnea and chest pain in patients [5]. The embolisation of tumor to systemic or pulmoner circulation is seen as 30\%$40 \%$ in patients [6]. Myxomas can be classified according to their smooth and irregular surface according to microscopic appearances. While solid type can cause vasoforming structures, papiller form is related to embolisms [7] .

The cardiac myxoma is identified by echocrdiography, cardiac CT or MRI imagings. When it was diagnosed, it should be resected because of embolisation, cardiovascular complications and sudden cardiac death [8]. The outcomes of surgery are good and the mortality rate of patients during operation is under 5\% [9]. But the surgery can cause development of arrhythmias and atrioventircular conduction defects in patients after surgery [10]. The recurrence is 


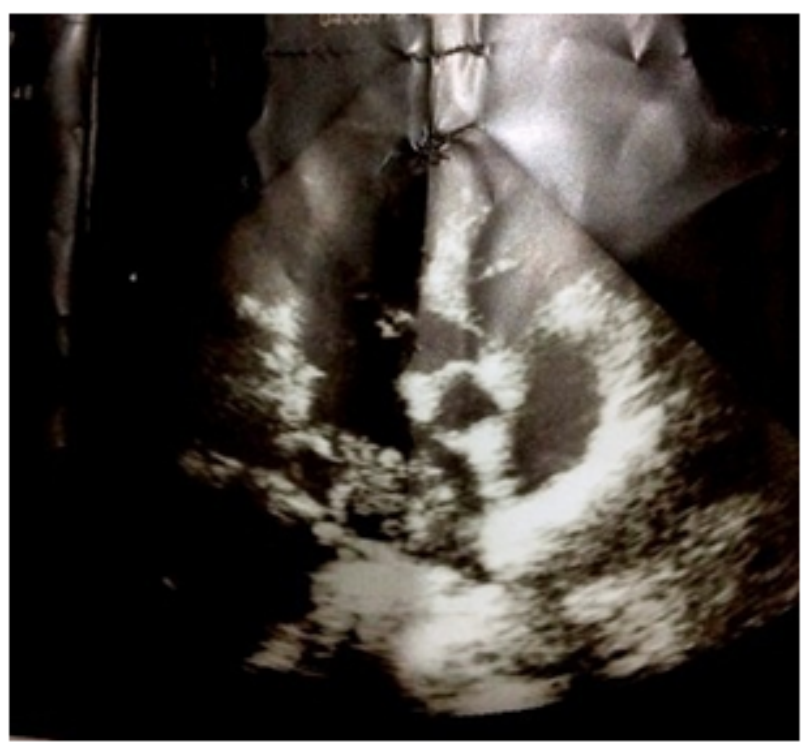

Figure 1. Image of atrial myxoma in apical 4-space view inechocardiography; fragmented appearance of myxoma

rarely after surgery exclude family story [9].

In this case, the patients was asymtomatic during long years although she had large sizes mxyoma. The mxyoma was detected incidentally in echocardiogram. We can explain it in two ways. One of them was slow growth of mixoma in years. The second way is that it did not cause mitral valve obstruction. But we thougt that the patient had hipotansion due to ventricular internal flow restriction although she had no symtoms. Perhaps she addicted her blood pressure levels in long time or the clinic presentation due to myxoma might not come out because of her physical limitation. The point that should not be missed was the possibility of a thrombus in pulmonary vein where myxoma originates.

Financial support and sponsorship

Nil.

\section{Conflicts of interest}

There are no conflicts of interest.

\section{REFERENCES}

[1] Gošev I, Paić F, Durić Z. Cardiac myxoma the great imitators: comprehensive histopathological and molecular approach. Int J Cardiol;164:7-20.

[2] Reynen K Cardiac myxomas N Engl J Med. 1995;.

[3] KY DPL. Chan AC. Tumors of the heart. A 20-year experience with a review of 12,485 consecutive autopsies. Arch Pathol Lab Med; 1993.

[4] Percell RL Jr et al. Atrial myxoma: case report and a review of the literature. Heart Disease;

[5] Constantine G, Shan K. Flamm SD, Sivananthan MU: Role of MRI in clinical cardiology. Lancet;363:2162.

[6] Singh SK, Kumar A, Tewarson V. Calcified left atrial myxoma with osseous metaplasia. Indian J Chest Dis Allied Sci;54:201-3.

[7] et al. Excision of atrial myxoma using robotic technology. J Thorac Cardiovasc Surg;139:1282-5.
[8] Bhan A, Mehrotra R, Choudhary SK, et al. Surgical experience with intracardiac myxomas: long-term follow-up. Ann Thorac Surg; 1998.

[9] Pinede L, Duhaut P, Loire R: Clinical presentation of left atrial cardiac myxoma. A series of 112 consecutive cases. Medicine (Baltimore);2001:80-3.

[10] Bakaeen FG, Reardon MJ, Coselli JS, et al. Surgical outcome in 85 patients with primary cardiac tumors. Am J Surg;186:641.

\section{AUTHOR BIOGRAPHY}

Cetin Sanlialp Sara MD, Department of Cardiology, Servergazi State Hospital, Denizli, Turkey 